\title{
LA ACTUACIÓN RACIONAL Y EL BIEN HUMANO
}

\author{
The rational agency and the Human good
}

\author{
Maximiliano Loria \\ Universidad Nacional de Mar del Plata (Argentina)
}

\begin{abstract}
Resumo: El presente artículo explicita, ordena y profundiza tesis fundamentales de Alasdair MacIntyre sobre la actuación racional y su necesaria vinculación con una teoría de los bienes. Muchas de las nociones aquí expuestas se encuentran esbozadas de forma heterogénea - en "estado germinal"- en diversos puntos de las principales obras del autor. He aquí entonces el valor principal de las presentes páginas. Ellas comienzan con la siguiente advertencia: los seres humanos no poseen una adecuada conciencia de su ser razonadores prácticos. Luego, se describe cómo el autor concibe y valora los diferentes tipos de bienes y se argumenta a favor de la necesidad de un bien supremo objetivo capaz de constituirse en criterio último de las acciones virtuosas. Todo ello orienta hacia una comprensión - cada vez más adecuada- de lo que significa vivir bien qua seres humanos. Asimismo, se muestra como una tal indagación no se agota en el plano de la reflexión moral sino que, en última instancia, debe situarse en una perspectiva metafísico-teológica..
\end{abstract}

Palavras-chave: Alasdair Maclntyre, investigación moral, actuación racional, bienes humanos.

Abstract: This paper discusses Alasdair Maclntyre's main thesis concerning rational agency and its necessary connection to a theory of goods. Many of the notions here exposed are formulated in a distinct way - in germinal state - through out the main works of Maclntyre: that is the signification of the paper. It begins with the following warning: human beings do not have an adequate counsciousness of their beings as practical reasoners. So it describes how the author conceives and values the different types of goods and argues for the necessity of an objective supreme good which is able of play the role of ultimate criteria for virtuous actions. All of that lead to an understanding - each time more adequate - of what means to live well qua human beings. Besides it shows how this kind of question is not answered in the plan of moral reflection, but that in the final it should be situated in a metaphysicaltheological perspective.

Keywords: Alasdair Maclntyre, Moral enquiry, rational agency, human goods. 
El presente artículo explicita, ordena y profundiza tesis fundamentales de Alasdair Maclntyre sobre la actuación racional y su necesaria vinculación con una teoría de los bienes. Muchas de las nociones aquí expuestas se encuentran esbozadas de forma heterogénea -en "estado germinal"- en diversos puntos de las principales obras del autor. He aquí entonces el valor principal de las presentes páginas. Ellas comienzan con la siguiente advertencia: los seres humanos no poseen una adecuada conciencia de su ser razonadores prácticos. Luego, se describe cómo el autor concibe y valora los diferentes tipos de bienes y se argumenta a favor de la necesidad de un bien supremo objetivo capaz de constituirse en criterio último de las acciones virtuosas. Todo ello orienta hacia una comprensión -cada vez más adecuada- de lo que significa vivir bien qua seres humanos. Asimismo, se muestra como una tal indagación no se agota en el plano de la reflexión moral sino que, en última instancia, debe situarse en una perspectiva metafísico-teológica.

\section{i. El ser humano como razonador práctico:}

En el capítulo séptimo de Animales Racionales y Dependientes (1999 [2001]) MacIntyre realiza una afirmación que permite sentar las bases para desarrollar una parte sustancial de las siguientes argumentaciones. El autor pone aquí en evidencia aquello que considera como presupuestos indispensables para el logro de un pleno desarrollo humano. Aquí sus palabras (1999: 67 [85]):

"El ser humano necesita aprender a verse a sí mismo como razonador práctico con respecto a los bienes, con respecto a lo que es mejor hacer en ocasiones concretas y con respecto a la mejor manera de vivir la vida. Sin aprender esto, no puede florecer". 
La cita precedente advierte sobre la profunda relación que Maclntyre establece entre el florecimiento ${ }^{1}$ del hombre y la necesidad de realizar una detenida reflexión crítica (se trata de un estudio de índole teórica pero realizado con una finalidad eminentemente práctica) acerca del valor de los distintos bienes particulares que, permanentemente, despiertan nuestro apetito. Dicha indagación conduce, de forma casi ineludible, a una reflexión complementaria respecto de cuál es la "mejor manera de vivir la vida" (lo cual, no es otra cosa que la búsqueda de una cierta resolución acerca de cuál es la mejor manera de ordenar, jerárquicamente, los diversos tipos de bienes) y sobre lo "que es mejor hacer en ocasiones concretas" (esto no es otra cosa que el intento de discernir, prudentemente, cómo "encarnar" los bienes en el presente de nuestras vidas).

Asimismo, previamente a ello, se impone destacar otra cuestión importante de la referencia anterior. Se trata de un aspecto de la realidad humana que se encuentra sobremanera oscurecido en el presente de nuestra cultura ${ }^{2}$ : "El ser humano -afirma Maclntyre- necesita aprender a verse a sí mismo como razonador práctico..."; es decir, debe recobrar y, consiguientemente, afianzar la conciencia de su ser razonador práctico -pues la plenitud humana se relaciona estrechamente con la consolidación de una manera de obrar íntimamente ligada al ejercicio de la deliberación ${ }^{3}$. Al subrayar esta necesidad, se busca indicar que esta potencialidad no siempre se actualiza en los seres humanos. O quizá, más claramente, habría que decir que no se desarrolla de un modo enteramente consciente y armónicamente acorde

\footnotetext{
${ }^{1}$ El término florecimiento es una noción esencial en la antropología macintyreana. Dicho concepto será descripto de manera más detenida en los siguientes apartados.

2 La cultura contemporánea es calificada por Maclntyre como predominantemente emotivista e individualista. Sobre dicha caracterización se hablará también de forma más completa a lo largo del presente estudio.

${ }^{3}$ Maclntyre parece expresar aquí la convicción tomista de que, a diferencia de los seres carentes de razón, el ser humano no alcanza los bienes específicos de su naturaleza por instinto o inclinación natural. Los animales no racionales pueden, "abandonándose" a su instinto, obtener todo aquello que les posibilite su pleno desarrollo -Tomás afirma que los animales alcanzan su fin "como movidos por otro". El hombre, en cambio, al encontrarse naturalmente dotado de entendimiento y libre voluntad, tiene potestad sobre sus actos y, en este sentido, "se mueve por sí mismo al fin" (Cfr. Tomás de Aquino, Suma de Teología, I-II C. 1 art. 2).
} 
con el florecimiento (no se pretende afirmar aquí que pueda darse el caso de personas que, sin carecer de impedimentos físicos para el uso de la razón, puedan vivir sin jamás discurrir prácticamente).

En síntesis: muchas de las características de la forma de vida generalmente imperante en nuestras sociedades dificultan la "autopercepción" de los agentes morales como razonadores prácticos.

Por lo tanto, el adentrarse en la comprensión de la actuación racional tal como Maclntyre la concibe, exige, en primer lugar, un sostenido esfuerzo en pos de la "reconquista" de nosotros mismos como razonadores prácticos. Lograr esto significa, en buena medida, recuperarnos qua ${ }^{4}$ seres humanos o, lo que es lo mismo, qua seres capaces de llegar a ser plenamente dueños -y responsables ante los demás- de nuestras acciones.

\section{ii. La noción de bien y los diversos tipos de bienes:}

“... la auténtica inteligencia práctica requiere [...] conocimiento del bien” (Maclntyre 2007: 155 [195])

El presente apartado se abocará al objetivo de dilucidar cómo Maclntyre comprende el concepto de bien y cómo "clasifica", valorativamente, los distintos bienes. En este sentido, aun cuando el autor discurre frecuentemente acerca de estos temas, no es usual encontrar en sus escritos una pormenorizada descripción de estas nociones. Al respecto, Lorenzo Izquierdo comenta lo siguiente (2007: 114):

"nuestro autor no da nunca una definición del bien acotada, pero es fácil ver [...] que su concepto de bien recoge la herencia aristotélico tomista".

\footnotetext{
${ }^{4} \mathrm{El}$ adverbio latino qua es frecuentemente utilizado por Maclntyre, especialmente en Animales Racionales y dependientes (1999 [2001]). Si bien dicha expresión latina, según sea el contexto en el que es utilizada, puede tener diversas traducciones en nuestra lengua, Maclntyre la utiliza con el sentido de «en cuanto». Así, la afirmación: "el hombre qua razonador práctico" equivale a: "el hombre "en cuanto» razonador práctico. A modo de ejemplo proponemos una cita de la obra mencionada en la que se pone enteramente de manifiesto el uso que el autor da al vocablo (1999: 64 [82]): "Pero cuando se habla si florecen o no los delfines qua delfines o si florecen o no los gorilas qua gorilas o si florecen o no los seres humanos qua seres humanos, se utiliza el verbo "florecer» en un solo y único sentido".
} 
De cuño específicamente tomista es la división del bien en fin (bien honesto y deleitable) y medios (bien útil) (Cfr. García López 1985:174). El autor parece asumir explícitamente esta distinción en su obra Animales Racionales y Dependientes cuando afirma la existencia de diversos "usos" del concepto básico de bien. En primer lugar, se atribuye el término bueno a determinadas cosas que son medios para obtener algo más, que es considerado como un bien en sí mismo. En segundo término, se dice que son buenas algunas otras cosas valoradas por sí mismas pero que no siempre deben ser asumidas por las personas, dependiendo ello de la situación particular en que se encuentren (en lenguaje escolástico se diría que son fines intermedios; bienes que son una cierta "mezcla" de fin y de aquello que se ordena al fin). Por último, Maclntyre reconoce que se atribuye la noción de bien a aquello que, siendo un bien en sí mismo, es también lo mejor para los seres humanos (el fin último para Tomás) (Cfr. Maclntyre 1999: 66- [84-85]).

Respecto a lo que se busca por sí mismo (el fin último o algún fin intermedio), hay que decir que es lo bueno en sentido propio. Y sucede que algo se apetece por sí en tanto se lo comprende como poseedor de una propiedad capaz de perfeccionar nuestro ser -ya sea absolutamente, o en un determinado aspecto y circunstancias. En palabras del autor (1999: 65 [83]): Es decir, lo bueno se atribuye a lo que beneficia al ser humano como tal, como a lo que le beneficia en situaciones específicas..."

El ya citado Lorenzo Izquierdo confirma esta posición (2007: 120):

“La propuesta de Maclntyre viene a ser, en conclusión, la recuperación de la idea de bien como aquello que perfecciona una naturaleza específica [...] Una concepción adecuada del bien [...] es, pues, el desarrollo de las facultades de la naturaleza humana, desarrollo que orienta el resto de los bienes particulares que la persona realiza...". 
Sabido es que a partir del llamado "giro aristotélico" que significó la aparición de Tras la Virtud (1981) $)^{5}$, el autor se constituye en representante y continuador de la tradición de pensamiento moral aristotélica y tomista. Por tanto, es preciso sostener que asume una particular manera de entender el bien y los bienes que recoge en lo sustancial las tesis de dicha tradición -lo cual, no implica que el autor utilice términos de cuño decididamente aristotélico o escolástico para su desarrollo de estos temas. Por consiguiente, como claramente lo expresan las citas arriba señaladas, bueno es todo aquello que posibilita al hombre el perfeccionamiento de sus facultades; bueno es lo que hace "ser más" a nuestro ser. Así, por ejemplo, el bien de nuestra inteligencia es la verdad (he aquí nuestro bien qua seres racionales); el alimento adecuado es el bien que posibilita nuestra subsistencia corporal (nuestro bien qua vivientes) y el ejercicio de la sexualidad en orden a la fecundidad de la vida, es el bien que posibilita la perpetuación de nuestra especie (nuestro bien qua animales). Ahora bien, respecto de todo aquello que es intrínsecamente bueno para nuestra naturaleza, siempre es necesario cuestionarse acerca de su oportunidad: las cosas buenas, no siempre nos convienen.

En contraposición, moralmente malo es todo aquello que contraría nuestro esencial desarrollo; todo aquello que va en "desmedro" de nuestro ser. La ignorancia y la falsedad son el mal de nuestro entendimiento; el exceso o carencia de alimentos adecuados destruye nuestra salud; el uso desordenado de la sexualidad amenaza nuestro equilibrio emocional y atenta contra nuestra dignidad personal, etc. Consiguientemente, a diferencia de lo que ocurre con lo bueno, no cabe aquí preguntarse por oportunidad alguna: las cosas malas, nunca nos convienen. Su adquisición, aun cuando pueda parecer una "ganancia" -puesto que siempre podemos desear cosas malas debido al aspecto de bien, de perfección, que todo ente posee-, constituye en realidad una pérdida.

\footnotetext{
${ }^{5}$ Puede consultarse al respecto la opinión de Javier De La Torre en su libro Alasdair MacIntyre ¿un crítico del liberalismo? (2005:11).
} 
Un tratamiento detenido y diferenciado de la noción de bueno-bien en la

filosofía de Aristóteles y Tomás de Aquino resultaría ajeno a los límites del presente estudio $^{6}$. Baste simplemente señalar cómo el propio Maclntyre confirma, de modo explícito, su fidelidad a los principios metafísico-morales de ambos pensadores (2007: $148[187-188]):$

“...las argumentaciones iniciales de Aristóteles en la Ética presumen que lo que G. E. Moore iba a llamar "falacia naturalista», no es una falacia en absoluto [...] Los seres humanos, como los miembros de todas las demás especies, tienen una naturaleza específica; y esa naturaleza es tal que tiene ciertos propósitos y fines a través de los cuales tienden hacia un telos específico. El bien se define en términos de sus características específicas. La ética de Aristóteles, expuesta como él la expone, presupone su biología metafísica".

Y también (1990:134 [175]):

\begin{abstract}
"Así, pues, el concepto de lo bueno sólo tiene aplicación a los seres en la medida en que son miembros de cierta especie o clase; Tomás de Aquino, en la cuestión 96, habla de nuestro bien qua ser, compartido con todos los otros seres, de nuestro bien qua ser animal, compartido con todos los otros animales y de nuestro bien qua ser racional, que es el bien común de los seres racionales".
\end{abstract}

\footnotetext{
${ }^{6}$ Para una descripción detallada de las nociones de bien/bueno en el pensamiento de Tomás de Aquino y de la tradición precedente puede consultarse el excelente análisis que realiza Jesús García López en el capítulo XI de su obra Metafísica Tomista... Ontología, Gnoseología y Teología Natural (Eunsa 2001). Asimismo, en Suma de Teología, I-Il C. 2 art. 1, el Aquinate brinda una condensada pero profunda explicación del modo en que en preciso juzgar las distintas riquezas humanas. El aquinate habla allí de bienes naturales (materiales), creados por Dios para cubrir nuestras necesidades corporales (alimentación, vestido, etc). El hombre no debe entregar su corazón a ellos ya que, si bien son muy necesarios y valiosos, constituyen tan solo un instrumento para apaliar dichas carencias. Estos bienes pueden intercambiarse mediante el dinero, riqueza artificial inventada por el hombre para servir de manera justa a dicho propósito. Para el aquinate las personas necias solo reconocen la existencia de estos bienes (de aquí que suelan tener un amor desordenado al dinero debido a que están convencidas de que podrán adquirir todos los demás bienes con su posesión). En contraposición, los sabios de quienes debe tomarse el criterio para valorar todas las cosas- reconocen la existencia de bienes espirituales (propios no ya del cuerpo sino del alma) y de Dios como Bien Supremo. Los bienes espirituales tales como la virtud moral, la amistad, la sabiduría, no pueden comprarse ni venderse, sino que se alcanzan gracias a nuestro esfuerzo por adquirir hábitos buenos y a la generosidad amorosa de nuestros semejantes.
} 
La ética, qua disciplina consagrada al conocimiento del bien humano, "presupone una biología metafísica"; presupone una comprensión filosófica de la naturaleza del hombre, de sus facultades específicas y de los hábitos necesarios para su armónico desarrollo en orden a la consecución del telos. A su vez, Maclntyre está convencido de que Aristóteles alcanza -al menos en parte- su entendimiento de la naturaleza humana (los gérmenes de su "biología metafísica") a través de la mediación de una indagación filosófica en torno a las formas de la vida social propias de su tiempo. Así, para Aristóteles, una parte importante del ser hombre estaría determinado por la búsqueda de la excelencia en el desempeño de un conjunto determinado de papeles sociales. Ser hombre es ser un ciudadano comprometido con la buena administración y la defensa de la polis; ser hombre es ser un padre de familia empeñado en la tarea de proveer todo lo necesario para el sustento material y el crecimiento en la virtud de los hijos; ser hombre es llevar adelante un oficio (mercader, campesino, soldado, filósofo, etc.) como una forma de contribuir al bien común y, al mismo tiempo, alcanzar la propia realización personal. Nadie puede desentenderse del adecuado cumplimiento de sus papeles sociales sin, de alguna manera, "desfigurar" su identidad humana.

Esta reflexión de cuño aristotélico en torno a la identidad esencialmente política del ser humano debe ser directamente enlazada con el concepto macintyreano de práctica. Según el autor, una práctica es una forma de actividad humana cooperativa, socialmente establecida, con determinados modelos de excelencia, autoridades y bienes (Cfr. Maclntyre 2007: 187 [233]) ${ }^{7}$. Sin embargo, lo que aquí

\footnotetext{
${ }^{7}$ La noción macintyreana de práctica engloba no solamente los intercambios específicamente morales (el ámbito de la praxis) sino también aquello que los griegos llamaban poiesis (el hacer humano; lo que hoy diríamos saber artístico-técnico-productivo). Así, al aprender -comunitariamente y bajo la guía de maestros- el bien de una techne particular (por ejemplo, el arte de la construcción), vamos paulatinamente comprendiendo el hecho de que la vida humana "como un todo" se encuentra teleológicamente estructurada, es decir, naturalmente orientada hacia unos fines específicos (Cfr. Lorenzo Izquierdo 2007:109). Asimismo, para una comprensión más acabada la noción de práctica remitimos al capítulo 14 de Tras la Virtud. En dicho capítulo, Maclntyre describe, por ejemplo, las posibles relaciones dadas entre las virtudes, las prácticas y las instituciones.
} 
interesa destacar es el hecho de que Maclntyre considera que las prácticas comunitarias constituyen algo así como el "hábitat natural" de nuestro aprendizaje moral. Es en dichas prácticas dónde, junto a padres y educadores, aprendemos a reconocer y valorar los distintos tipos de bienes y, como consecuencia de ello, a forjar -poco a poco, según crecemos en edad y experiencia- una idea cada vez más adecuada de lo que es el bien del hombre. ${ }^{8} \mathrm{Y}$ así lo destaca también el ya citado Lorenzo Izquierdo al afirmar que (2007: 102-103):

“...distinguir y aplicar el bien son cosas que se aprenden prácticamente, viviendo [...] Se aprende cuál es el bien común y cuáles son los bienes individuales [...] en actividades cotidianas compartidas y en la evaluación de las alternativas que imponen esas actividades".

Esto último permite vislumbrar que para el pensamiento macintyreano es de capital importancia asumir una comprensión del ser humano que ponga de manifiesto la íntima vinculación que existe entre las personas y la comunidad. Solo puede entenderse adecuadamente al hombre si se lo reconoce como esencialmente ligado, desde su nacimiento hasta su muerte, a diversas comunidades, constituidas no solamente a partir de lazos de sangre, sino también -y especialmente- en torno a creencias compartidas $^{9}$. Y así, claramente, lo expresa el autor (2007: 155 [196]):

“...la realización del bien humano presupone por descontado un margen amplio de acuerdo en esa comunidad acerca de los bienes [...] Este compartir es esencial y primario para la constitución de cualquier forma de comunidad".

\footnotetext{
${ }^{8}$ Puede observarse en el autor una estrecha analogía entre su modo de entender la relación existente entre las prácticas comunitarias y nuestro aprendizaje moral de la noción de bien y su precedente interpretación del vínculo dado entre las formas de la vida social ateniense y la "biología metafísica" de Aristóteles.

${ }^{9}$ En este punto se expresa, una vez más, la adhesión de Maclntyre al pensamiento del aquinate (1990: 193 [242]): “...precisamente esa clase de creencia compartida que es característica de aquellas comunidades de investigación y práctica morales sólo dentro de las cuales, según la concepción tomista, pueden los bienes humanos identificarse de modo suficiente y perseguirse".
} 
No existe verdadera comunidad en ausencia de un núcleo de creencias morales compartidas. Precisamente en esto se distingue a las comunidades de las asociaciones de individuos; de los grupos humanos circunstancialmente relacionados a causa de intereses comunes (aun cuando pueda parecer extraño, este último tipo de asociación no solo puede darse -como espontáneamente se imaginará- en una empresa; también puede ocurrir que personas vinculadas por asuntos "más espirituales" no constituyan una comunidad auténtica). Ante todo se destaca aquí una tesis primordial para el autor: la pertenencia a una comunidad es esencial y primaria para que las personas maduren en la comprensión de los distintos bienes que, en su diversa jerarquía, mejor armonizan con nuestra naturaleza. Y así, elocuentemente, lo denuncia el propio MacIntyre (2007: 258 [317]):

“...los bienes [...] sólo pueden descubrirse entrando en relaciones constitutivas de comunidades cuyo lazo fundamental sea la visión y la comprensión común de esos bienes. Arrancarse uno mismo de esa actividad [...] aislarse de la comunidad que encuentra su fin y su propósito en tales actividades, será excluirse de encontrar bien alguno fuera de uno mismo. Será condenarse al solipsismo moral..."

Según se dijo, el autor no propone una catalogación exhaustiva de los distintos bienes. No obstante, pueden mencionarse algunas excepciones a esta tendencia. En este sentido, al finalizar el capítulo II de Justicia y Racionalidad (1988), Maclntyre se detiene a examinar la noción de arete en la "imaginación" homérica ${ }^{10}$. La indagación que realiza en torno a la idea de virtud plasmada en la poesía de Homero constituye una eficaz introducción a la concepción macintyreana de los bienes. En dicha investigación, el autor sostiene la necesidad de destacar una importante distinción en la idea de logro que toda arete conlleva. Maclntyre afirma que la sociedad homérica percibió en el concepto de logro dos aspectos sumamente

\footnotetext{
${ }^{10}$ Este capítulo se encuentra dedicado a indagar cómo fueron entendidas la acción y la justicia en el mundo homérico. MacIntyre profundiza aquí sus estudios histórico-filosóficos precedentes en torno a la noción de virtud en la sociedad heroica y sus posteriores incidencias en la cultura griega clásica de la Atenas del siglo V (Cfr. caps. 10 y 11 de Tras la Virtud).
} 
diferentes: logro puede ser entendido como excelencia; o bien, puede ser asimilado con la idea de victoria. Al mismo tiempo, Maclntyre destaca el hecho de que ambas dimensiones, tanto en los tiempos homéricos como en el presente, no siempre se han dado de forma conjunta; es decir, existen circunstancias -ya azarosas; ya voluntariamente constituidas- que pueden determinar que la persona más excelente no alcance el premio de la victoria. El autor lo remite en estos términos (1988: 27-28 [43]):

\begin{abstract}
“Homero mismo percibía con meridiana claridad que la noción de logro que incorpora arete tiene dos dimensiones distintas, aunque muy íntimamente relacionadas. Lograr algo es sobresalir, aunque también significa ganar. ¿Cuál es la relación entre el logro entendido como excelencia y el logro entendido como victoria? [...] con la expresión «más excelente» no queremos decir "victorioso»; "más excelente, pero perdedor» no es una contradicción como reconoció Héctor cuando, tras afirmar su preeminencia propia en cuanto guerrero, no obstante prevé su propia derrota (La llíada VI, $440-465)^{\prime \prime 11}$.
\end{abstract}

Si el agon de la vida fuese generalmente justo; si se diera el caso de que las condiciones de existencia fuesen mayoritariamente dispensadas (por parte de aquellos a quienes corresponde distribuir el bien común) a partir del mérito y la necesidad objetiva; si así ocurriese, entonces, el más excelente sería también -al menos casi siempre- el victorioso. Pero las pretéritas circunstancias homéricas, así como las que cabe hoy también toca afrontar, muestran sobremanera que no necesariamente el más excelente en el orden de las virtudes es aquel que accede al "premio" del reconocimiento comunitario. Es más, contrariamente a ello, asistimos a una sociedad que suele promocionar todos aquellas formas de conducta que, en cuanto excesos, se apartan del justo medio propio de la vida virtuosa ${ }^{12}$.

\footnotetext{
${ }^{11}$ En el mencionado capítulo 10 de Tras la Virtud, el autor había afirmado ya la necesidad cuestionar, en el propio "mundo homérico", el establecimiento de una estricta equivalencia entre "ser victorioso en el agon" y "poseer una buena vida» (o bien, entre "perder en combate» y "fracasar en el buen vivir»). El estudio de la cultura homérica se constituye para Maclntyre en una oportunidad para cuestionar "qué significa realmente perder y ganar y cuanto importa" (Cfr. 2007: 130 [166]).

${ }^{12}$ En la obra de MacIntyre resulta frecuente encontrar, al momento de abordar históricamente una cuestión (por ejemplo, "La concepciones rivales de la virtud en la Atenas clásica"), permanentes 
A continuación Maclntyre destaca el hecho de que la búsqueda permanente y unilateral de la victoria; la intención de triunfo como móvil principal de las acciones, se encuentra estrechamente emparentada con el deseo desordenado de aquello que el autor denomina bienes de efectividad o eficacia, los cuales, no son otra cosa que aquellas recompensas externas -tales como el dinero, la fama y el poder-que suelen otorgarse a las personas que se sobresalen en alguna de aquellas actividades que son relevantes para una sociedad determinada: la guerra en los tiempos homéricos; los juegos olímpicos y los certámenes poéticos en la Grecia clásica; los maestros de teología en la universidad del París del siglo XIII; los futbolistas en nuestra sociedad actual, etc.

Aquellos que consagran su vida a la conquista de los bienes externos de efectividad, utilizan su capacidad para destacarse en alguna actividad determinada solamente como un medio para el logro de su propio provecho -mientras que habitualmente se desentienden del bien común de la sociedad a la que pertenecen. Esta convicción se encontraba ya explícitamente formulada en Tras la Virtud. Al respecto, puede proponerse la siguiente cita (2007: 190 [237]):

\footnotetext{
"Es característico de los bienes externos que, si se logran, siempre son propiedad y posesión de un individuo. Además, típicamente son tales que cuantos más tenga alguien menos hay para los demás [...] Los bienes externos son típicamente objeto de una competencia en la que debe haber perdedores y ganadores".
}

Asimismo, interesa destacar que el autor nombra de esta forma singular a dichos bienes, debido precisamente al hecho de que aquellos que los persiguen suelen ser enteramente eficaces en encontrar los medios más adecuados (efectivos) para su consecución -como era de esperar, estos sujetos difícilmente se cuestionan acerca del

alusiones a cómo se entiende y "vive" dicho tema en la sociedad contemporánea. Maclntyre es, fundamentalmente, un crítico de la modernidad y, en este sentido, procura permanentemente poner de manifiesto las discrepancias existentes entre aquello que él llama visión clásica del hombre (enfoque de raigambre marcadamente aristotélico y tomista) y el presente modo liberal de entender a los individuos y la sociedad. Cuando se considere oportuno, también se indicarán aquí dichas diferencias y tensiones. 
sustento moral de sus estrategias. De aquí que, tanto en las personas como en las sociedades, pueda establecerse una relación inversamente proporcional entre esta clase de bienes y el predominio de las virtudes. Maclntyre lo afirma en estos términos (2007: 196 [244]):

\begin{abstract}
"Por tanto, en una sociedad concreta donde hubiera llegado a ser dominante la búsqueda de bienes externos, cabría esperar una decadencia del concepto de las virtudes, hasta llegar casi a la desaparición total, si bien podrían abundar los simulacros" ${ }^{\prime 3}$.
\end{abstract}

Ahondando en su propuesta, Maclntyre contrapone los mencionados bienes externos de efectividad con aquello que denomina bienes internos de excelencia ${ }^{14}$, es decir, aquellos bienes que pueden alcanzarse mediante la realización excelente de una práctica comunitaria. Quienes persiguen este tipo de bienes, no buscan ya solamente su propio beneficio, sino que son capaces de subordinar su provecho personal al bien común. Al contrario de aquello que ocurría con los bienes externos, cuantos más bienes de excelencia logre una persona conquistar, más podrá la comunidad beneficiarse. Y así el autor lo señala expresamente (2007: 190 [237]): “Los bienes internos son resultado de competir en excelencia, pero es típico de ellos que su logro es un bien para toda la comunidad que participa en la práctica".

Además, lo que aquí se persigue no es simplemente destacarse en cualquier actividad; aquí se busca la excelencia solo en el ejercicio de aquellas prácticas por medio de las cuales puede una persona realizarse como ser humano. Esto supone que pueden existir trabajos socialmente relevantes $y$, sin embargo, intrínsecamente incompatibles con el pleno desarrollo moral del hombre. En nuestro tiempo, Maclntyre

\footnotetext{
${ }^{13}$ Este tipo de simulacro se encontraría paradigmáticamente representado por la "virtud" propia de cierto tipo de sofistica: quiere únicamente vencer y ganar para sí mismo de los frutos de la victoria. Todos los demás están para ser usados o vencidos. El sofista hace del éxito la única meta de la acción. El poder es la herramienta para conseguir el éxito y la "virtud" aquella cualidad que asegura el alcanzarlo (Cfr. Maclntyre 2007: 139 [176]).

${ }^{14}$ En modo en que aquí se comprende y expresa la "clasificación" macintyreana de los bienes coincide casi enteramente con la propuesta de Lorenzo Izquierdo. Cfr. (2007: 106).
} 
propone la "pericia gerencial" como un ejemplo característico de este último tipo de actividad $^{15}$. Frente a estas actividades, se ubican aquellas prácticas enteramente compatibles con el desarrollo pleno y armónico de nuestras facultades naturales: entregarse al estudio de la verdad y procurar generosamente enseñarla; gobernar prudentemente en orden al bien común; edificar de un modo que se respete el entorno natural; hacer poemas que realcen la belleza de las palabras y las nobles acciones; etc.

Como complemento de lo afirmado acerca de la relación existente entre los bienes externos y las virtudes (a menor virtud mayor predominio social de búsqueda casi exclusiva de estos bienes) ha de destacarse que los bienes de excelencia pueden reconocerse y obtenerse solamente por medio de las virtudes. Al mismo tiempo, debe alertarse sobre la posible incompatibilidad que, en muchas ocasiones, puede surgir en la persecución de ambas formas de bien. Esto significa que las mismas virtudes pueden convertirse, llegado el momento, en un obstáculo para la obtención de bienes externos. Maclntyre lo enuncia del presente modo (2007: 196 [243]):

“...sin las virtudes no sólo no puede existir reconocimiento alguno de lo que he llamado bienes internos, sino sólo de los bienes externos al contexto de las prácticas. [...] La posesión de las virtudes, y no sólo su apariencia y simulacro, es necesaria para lograr los bienes internos; en cambio, la posesión de las virtudes muy bien puede impedirnos el logro de los bienes externos"

Y también (1988:32 [48])

“...la persecución sistemática de la excelencia, en algún área o áreas, llega a ser incompatible con la persecución de los bienes de las riquezas, del status y del prestigio, las diferencias entre estos dos tipos de persecución y entre los bienes que son sus objetos se vuelven muy claras".

15 Maclntyre denomina "pericia gerencial" a la ficción cultural de poseer unos conocimientos "científicos" determinados que convertirían a un individuo en especialista manipular medios (fundamentalmente recursos humanos) para obtener fines predeterminados (recursos materiales). Cfr. Tras la Virtud caps. 7 y 8. 
Por lo general, es necesario poseer algunas excelencias auténticas para tener parte en aquellos bienes que son fruto de la victoria; difícilmente alguien podría sobresalir y, consiguientemente, recibir las recompensas externas del dinero y la fama, sin haber cultivado de modo pleno alguna de sus capacidades (aun cuando puede darse el caso de que alguien obtenga azarosamente este tipo de bienes). No obstante, no sería verdaderamente virtuoso -sino solo aparentemente tal- todo aquel que se destacase en el cumplimiento de alguna función social movido únicamente por el deseo de obtener dinero o de alcanzar reconocimiento público y poder. Del mismo modo que, por ejemplo, no es verdaderamente moderada aquella persona avara que aquieta sus pasiones con la sola finalidad de no encontrarse en la situación de tener que "malgastar" con otros su dinero; ni tampoco es auténticamente justo todo aquel que devuelve lo que debe, no debido a que reconoce su obligación moral, sino a causa de la expectativa de recibir, en el futuro, algún beneficio mejor. Maclntyre distingue además entre virtud y aquello que hoy podría denominarse habilidad profesional. Una virtud es una cualidad que puede ser ejercida en situaciones diversas en muchas de las cuales deberá renunciarse a toda pretensión de eficacia, cuestión que es totalmente incompatible con el desarrollo de una habilidad profesional (Cfr. Maclntyre 2007: 205 [253]).

En definitiva, es manifiesto que la noción de arete asumida por parte de aquellos que se abocan, principalmente, al cultivo de uno de estos tipos de bienes, difiere radicalmente de la idea de virtud en la que se sustentan los que se entregan a la persecución de los bienes pertenecientes a la otra clase. Y así lo confirma Maclntyre (1988:32 [49]): “...lo que se toma por virtud desde la perspectiva de los bienes de la eficacia, a menudo será muy distinto de lo que se toma por virtud desde el punto de vista los bienes de excelencia".

Análogamente a lo que sucede con el concepto de virtud, el discurrir práctico de quienes buscan los bienes de excelencia posee una estructura y un contenido diferente del que realizan aquellos que persiguen los bienes de eficacia. Se esboza aquí 
la relación existente entre razonamiento práctico y bienes. Como es sabido, el obrar humano tiene su principio en la consideración de un bien particular -ya de excelencia; ya de efectividad- que "despierta" el apetito; la conquista de dicho bien se constituye en motivo formal para la acción. Al respecto, dice el autor (1999: 24 [38]) "...si se le pide a una persona que exprese la razón por la que ha llevado a cabo una determinada acción, ésta señalará el bien al que ha servido la acción, el bien hacia cuya realización estaba orientada".

Ahora bien, desde la óptica macintyreana, el razonamiento de las personas que buscan la excelencia se detiene en considerar cómo el bien concreto deseado puede armonizar con el bien integral de la propia persona y con el bien común de la comunidad a la que se pertenece. En contraposición, aquellos que buscan los bienes externos del éxito, la fama y el poder, discurren con el solo objetivo de alcanzar sus preferencias, sin reparar en las consecuencias que, a partir de ello, puedan sobrevenir para la vida social: no hay aquí noción bien común que pueda ponerse por "encima de" la búsqueda espontánea del provecho propio ${ }^{16}$. Puede ilustrarse lo afirmado con las siguientes citas (1988: 28 [43]):

“...ambos tipos de logros, el de la excelencia y el de la victoria, requieren un razonamiento práctico eficaz; y que es importante conocer si el tipo de razonamiento práctico necesario para el logro excelencia se diferencia de aquél necesario para el logro de la victoria y cómo se diferencian".

Además (1988: 43 [57]):

“... lo que se toma como una buena razón para actuar es muy diferente para aquellos para los cuales el contexto del razonamiento práctico se recibe de una forma de actividad especificada por uno o más de los bienes de la

\footnotetext{
${ }^{16}$ Se trata de una forma de ejercer la praxis en la que los agentes "morales" no se detienen a deliberar sobre los fines (los deseos subjetivos), en el sentido de procurar discernir si se encuentran o no racionalmente justificados. La pericia en dicha forma de razonamiento práctico consiste tan solo en una suerte de "adiestramiento" en el detectar, astutamente, cuál es el camino más eficaz para la consecución de los propios deseos. Este modo de discurrir es característico de lo que Maclntyre denomina racionalidad práctica liberal.
} 
excelencia, que para aquellos para quienes el contexto del razonamiento práctico se recibe de una comprensión de la vida social como un foro en el cual cada individuo y cada grupo de individuos busca maximizar la satisfacción de sus propios deseos y necesidades. Estos son dos razonamientos prácticos y no uno solo".

A partir de lo dicho, podría concluirse que el autor da, en referencia a los bienes externos, una calificación moral enteramente negativa; podría precipitadamente juzgarse que estos son, en realidad, bienes tan solo aparentes. Pero MacIntyre confirma su bondad en tanto que útiles (medios) para el sostenimiento de prácticas e instituciones ${ }^{17}$ indispensables para el normal desarrollo de una comunidad. En su ausencia, por ejemplo, algunas virtudes difícilmente podrían ejercerse: cómo ser magnánimo o generoso sin poseer riquezas; cómo llevar adelante la justicia distributiva sin poseer poder político. El autor llega a decir que ninguna persona puede enteramente despreciarlos sin caer en un cierto grado de hipocresía (Cfr. Maclntyre 2007: 196 [243]). Sin embargo, su búsqueda conlleva desorden moral cuando, al modo de fines, se los desea exclusivamente 0 , al menos, en primer lugar.

Por lo tanto, se torna aquí manifiesta la "clasificación" jerárquica que Maclntyre realiza de los distintos tipos de bienes: los externos (bienes útiles-simples medios) deben subordinarse a los internos, puesto que solo por medio de la conquista de la excelencia en aquellas actividades comunitarias acordes con el florecimiento puede el hombre adentrarse en la senda de la buena vida. Es decir, alcanzando la excelencia en una práctica (algo que, según se destacó arriba, exige la posesión de auténticas virtudes) se logra algo más -y más importante-que la sola conquista de sus bienes internos; la realización virtuosa de dicha actividad posibilita la obtención de aquello que Maclntyre denomina como el bien de una cierta clase de vida o, lo que es lo mismo, cierto modo de buen vivir; o bien, en otras palabras, el buen vivir, al menos

\footnotetext{
${ }^{17}$ Las instituciones están necesariamente comprometidas con los bienes externos. Necesitan dinero y se estructuran en términos de jerarquía y poder. Ninguna práctica puede sobrevivir largo tiempo sin ser sostenida por instituciones pero, en contrapartida, los ideales y la creatividad de la práctica son siempre vulnerables a la codicia de la institución (Cfr. Maclntyre 2007: 194 [241])
} 
en parte. He aquí, en palabras del autor, esta idea particularmente referida a la práctica artística (2007: 190 [236]):

\footnotetext{
"Porque lo que el artista encuentra en el curso de la búsqueda de la excelencia [...] es el bien de cierta clase de vida [...] Para el pintor, el vivir como pintor una parte más o menos grande de su vida es el segundo tipo de bien interno a la práctica de la pintura".
}

En síntesis: toda persona que aspire a encaminarse hacia el telos del florecimiento debe subordinar la eficacia en obtener riquezas, reconocimiento y poder a la búsqueda de su propia excelencia y la de aquellos que tiene bajo su cuidado. Los bienes de efectividad, dado el caso de que uno haya tenido la capacidad y la fortuna de obtenerlos, deben ser utilizados como "herramientas" para desplazar las posibles barreras naturales, humanas e institucionales que puedan levantarse contra el progreso moral de la propia comunidad. La acumulación de riqueza nunca ha de tomarse como un fin en sí mismo, sino tan solo como un medio para obtener los indispensables recursos para el adecuado desarrollo de las prácticas. El ejercicio del poder debe ser visto como una forma de servicio al bien común y no como un modo de autoafirmación arbitraria del yo mediante el subyugamiento de los semejantes.

El conjunto de la argumentación precedente permitió "arrojar luz" sobre una relevante tesis en el pensamiento moral del autor: la aptitud para reconocer las diversas clases de bienes y la capacidad de juzgar acerca de su diferente valor, constituyen requisitos indispensables para el desarrollo y pleno ejercicio de la actuación racional.

\section{iii. La vida buena como un todo:}

La precedente reflexión sobre los bienes condujo a una comprensión parcial (provisoria, incompleta) de la noción de buen vivir asumida por el autor: la conquista de la excelencia en las prácticas (de los bienes internos a las prácticas) permite alcanzar el bien de cierta clase de vida, el buen vivir en cierto modo. En este punto, la 
argumentación se propone dilucidar qué significa la buena vida como un todo; es decir, no ya el vivir bien como pintores, filósofos o poetas sino, absolutamente, qua seres humanos.

El vivir bien como seres humanos presupone entonces no solamente la posesión de una adecuada valoración de los diversos tipos de bienes particulares, sino también la aptitud para reconocer cuál es $-y$, consiguientemente, acceder a su progresivo conocimiento y adhesión- el bien supremo que ha de postularse como el verdadero fin último de las acciones humanas.

En relación a esto, Maclntyre pone en evidencia una cuestión no siempre advertida por los agentes morales: la particular forma de vida de cada persona (sus elecciones cotidianas; el tiempo concreto que dedica a unas actividades en desmedro de otras, etc.) expresa, en sí mismo, un modo jerárquico de ordenar los bienes y, en este sentido, pone también de manifiesto cuál es el telos que -más o menos conscientemente- persigue al realizar el conjunto de sus acciones. En cada momento de su existencia, cada ser humano "pone su corazón" en un determinado bien al que, equivocadamente o no, califica de superior. Maclntyre lo afirma en estos términos (2006: 70-71 [120-121]):

\footnotetext{
“También nos enfrentamos a ese nivel de la praxis cotidiana a la cuestión de qué lugar conceder en nuestras vidas a la multiplicidad de bienes que hemos aprendido que nos es posible alcanzar. Cada vida individual expresa ya, claro está, una respuesta a esta cuestión. Cada uno de nosotros, viviendo como vive, expresa, habitualmente de forma implícita e irreflexiva, alguna concepción acerca de cuál es, con nuestras características particulares, en nuestras circunstancias particulares y con nuestras dificultades particulares, la mejor forma de vivir para nosotros. Esto es, expresamos alguna concepción acerca de lo que es la felicidad humana [...] por medio de la forma en que algunos bienes les atribuimos un lugar mayor y más importante en nuestras vidas, a otros un lugar menor y algunos ninguno en absoluto [...] Pero nuestro único fin último se revela en la forma en que organizamos esos otros bienes, en el bien o bienes a los que otorgamos la posición más elevada..."
}

Evidentemente, el autor considera que la actuación racional es totalmente incompatible con una actitud despreocupada y acrítica respecto de los bienes. Es 
imposible vivir qua seres racionales sin detenerse jamás a reflexionar sobre el singular "acomodamiento" de bienes que se "encarna" en nuestra vida -y sobre si dicha espontánea ordenación (seguramente, en gran medida, culturalmente heredada) armoniza o no con el auténtico desarrollo de nuestra naturaleza. Una vez más, MacIntyre lo que expresa de este modo (2006: 71 [121]):

\footnotetext{
"Lo que exige de nosotros la racionalidad es que nos preguntemos si hay buenas razones, y cuáles son, para considerar el concepto de la felicidad humana encarnado hasta ese momento en nuestras acciones y relaciones el más adecuado de entre los que disponemos. ¿Es cierta la explicación de la naturaleza humana que presupone nuestra concepción [de felicidad]?".
}

Se hace patente aquí la necesidad de una cierta metanoia, de una "conversión" moral primera que, a partir de la conquista de una plena lucidez respecto de dónde se encuentra en realidad puesta nuestra fidelidad primera ("el tesoro de nuestro corazón"), nos introduzca en la senda de una búsqueda sincera y comprometida (personal y comunitaria) del verdadero bien humano. Porque este "ir tomando conciencia" de cuál es la mejor manera de vivir; el entendimiento del hacia dónde debe tender la totalidad de nuestras acciones, no es algo que se alcanza "de una vez y para siempre"; no es una cuestión que se aprende a partir de un riguroso estudio bibliográfico o de la metódica aplicación a una meditación "solipsística" -si bien la lectura y la reflexión personal son una herramienta imprescindible para ir adquiriendo cierta luz intelectual sobre el tema. Es en el mencionado ámbito de las prácticas comunitarias, en el intercambio dialógico y en la visión del ejemplo de nuestros semejantes, donde dicha indagación personal se forja, se cuestiona, se nutre y se "pone a prueba": ¿cómo fue el "desenlace" de la vida de aquellos familiares a quienes solo parecía importar el dinero?, ¿cuál es el valor académico de la clases de aquellos docentes a quienes solo parece importar la obtención de cargos?, ¿acaso no parece feliz aquella mujer que, habiendo sido abandonada por su marido, tuvo que "dejar a un lado" muchos de sus proyectos personales y consagrar su vida a la obtención del sustento material y educación de sus hijos? Lo importante es entonces la 
determinación a la búsqueda; el asumir los riesgos, incidentes, frustraciones y distracciones que todo proyecto existencial conlleva; es la constancia ${ }^{18}$ en el esfuerzo por intentar comprender "por dónde pasa", verdaderamente, la buena vida. De este modo, aun cuando muchas veces parezca que se marcha "a tientas", el hábito de examinar detenidamente cómo estamos viviendo $-\mathrm{y}$ cómo hemos de vivir- es ya también, de algún modo, adentrarse decididamente en el camino de la buena vida humana. El autor lo propone en estos términos: (2007: 219 [271]): "Hemos llegado entonces a una conclusión provisional sobre la vida buena para el hombre: la vida buena para el hombre es la vida dedicada a buscar la vida buena para el hombre"19.

En síntesis: sin una cierta idea del telos humano no puede existir principio alguno para la búsqueda -pues lo último en ser alcanzado debe ser lo primero en la intención de los agentes. Se trata poder vislumbrar un concepto de bien supremo que permita una ordenación jerárquica del resto de los bienes. Pero "lo bueno y lo mejor" entendido como telos no es algo que esté plenamente caracterizado desde comienzo. Sólo en el transcurso de la búsqueda, y mediante el enfrentamiento con los varios riesgos que toda búsqueda implica,-- se podrá ir poco a poco conociendo dónde radica el auténtico bien humano (Cfr. Maclntyre 2007: [270]).

\footnotetext{
${ }^{18}$ La constancia es una virtud especialmente necesaria para "hacer frente" a los desafíos de nuestro presente cultural, pues es manifiesto que a todos aquellos que somos "hijos de este tiempo" se nos hace particularmente difícil asumir proyectos existenciales a largo plazo, o que impliquen un compromiso "para siempre". Maclntyre destaca este hecho cuando en Tras la virtud menciona a la novelista Jane Austen, no solamente como continuadora de la tradición clásica de la virtudes, sino también como alguien que -mediante su obra- ha hecho un efectivo aporte a dicha tradición al destacar el papel esencial de la constancia en la construcción de una vida unificada. La siguiente cita es sumamente ilustrativa al respecto (2007: 242 [297]): “...en la vida ética los compromisos y responsabilidades con el futuro surgen de episodios pasados en que se concibieron obligaciones, y los deberes asumidos unen el presente con el pasado y el futuro de modo que conforman así la unidad de la vida humana [...] En la época de Jane Austen esa unidad ya no podía tratarse como una mera presuposición o contexto de la vida virtuosa. Ha de ser continuamente reafirmada, y su reafirmación más en los hechos que en las palabras es la virtud que Jane Austen llama constancia. La constancia es fundamental [...] es una virtud que las mujeres practican mejor que los hombres. Y sin constancia, todas las demás virtudes pierden su objetivo hasta cierto punto".

${ }^{19}$ Es imposible no rememorar en la conclusión macintyreana el eco de la conocida advertencia socrática: "una vida sin examen no tiene objeto vivirla para el hombre" (Cfr. Platón, Apología de Sócrates, 38a.).
} 
La necesidad de realizar, en tanto que parte esencial de la vida buena, una constante indagación sobre cuál es el supremo bien de los seres humanos se vuelve especialmente patente cuando las personas se ven apremiadas a resolver ciertos conflictos que pueden surgir como consecuencia de su propósito de fidelidad a las exigencias de prácticas diversas: siempre puede darse el caso de que, por ejemplo, la excelencia en el ejercicio de la docencia universitaria se torne, al menos por momentos, incompatible con la excelencia en el sostenimiento de la comunidad familiar; o que el vivir bien como músicos implique, en ocasiones, que tenga que desatenderse a otros compromisos relacionados con actividades de beneficencia. Surge entonces, inevitablemente, la pregunta por el sentido último de nuestro compromiso con las distintas prácticas: ¿es posible disponer de un criterio fundado (es decir, un principio que no sea arbitrario, fundado en ocasionales y subjetivas preferencias) para decidir entre fidelidades en conflicto?, ¿existe un bien humano "por encima de" los particulares bienes de excelencia fruto de las distintas prácticas; un determinado bien supremo "a cuya luz" pueda juzgarse el valor y oportunidad de estas mismas prácticas?

Como puede observarse, el desarrollo y sólido ejercicio de la actuación racional necesita "apoyarse" en un entendimiento -cada vez más adecuado- del telos de la vida humana, puesto que, en última instancia, las acciones voluntarias pueden comprenderse a partir de la concepción de bien humano asumida por la persona que las realiza. Cuando dicha visión no se logra (ya sea debido a negligencia personal o por falta del necesario auxilio comunitario) o momentáneamente se oscurece a causa de alguna pasión desordenada, ocurre que el ser humano queda como "huérfano", sin elementos para discriminar, más allá del propio deseo, como priorizar entre las diversas prácticas y papeles que conforman su vida. A propósito de esto, Maclntyre apunta lo siguiente (2007: 202-203 [250-251]):

"Pero los bienes internos a las prácticas, incluyendo los bienes internos a la práctica de promover y mantener formas de comunidad, necesitan 
valorizarse y jerarquizarse de alguna manera [...] salvo cuando exista un telos que trascienda los bienes limitados de las prácticas y constituya el bien de la vida humana completa, el bien de la vida humana concebido como una unidad, ocurre que cierta arbitrariedad subversiva invade la vida moral..."

La conclusión precedente constituye una invitación a profundizar la reflexión sobre el "lugar" que ocupan las virtudes en la configuración macintyreana del buen vivir. Se ha destacado ya el papel fundamental de las virtudes en la conquista de los bienes de excelencia propios de las prácticas. Ahora se hace patente la necesidad de su "auxilio" para progresar en el conocimiento y "persecución" del telos de la vida humana completa: sin virtudes no se puede evitar la negligencia en la búsqueda, ni "sortear" las permanentes distracciones de la pasión. Sin embargo, si bien puede calificarse a las virtudes como de medios para el logro de una buena vida humana, no se debe pensar en ellas al modo de simples bienes útiles. Respecto de ello, el autor propone asumir una distinción tomista -aun cuando de genuino raigambre aristotélico- que establece una diferencia entre aquello que serían medios internos y externos a un fin dado. Así, cuando el fin propuesto puede ser caracterizado con independencia de los medios que posibilitan alcanzarlo, se habla entonces de medios externos, meramente instrumentales. Caso contrario, los medios mismos constituyen una parte esencial del fin propuesto, con lo cual, nos encontramos frente a medios internos. Así lo enuncia Maclntyre (2007: 184 [229-230]):

\footnotetext{
“Es necesario recordar que aunque Aristóteles trata la adquisición y ejercicio de las virtudes como medios para un fin, la relación de los medios al fin es interna y no externa. Hablo de medios internos a un fin dado cuando éste no puede caracterizarse adecuadamente con independencia de la caracterización de los medios. Así sucede con las virtudes y el telos que en opinión de Aristóteles es para el hombre la vida buena. El mismo ejercicio de las virtudes es el componente fundamental de la vida buena del hombre. Esta distinción entre medios internos y externos para un fin [...] no la expone Aristóteles [...] pero es una distinción esencial si queremos entender lo que Aristóteles se proponía. La distinción la plantea explícitamente Tomás de Aquino en el curso de su defensa de la definición de virtud de San Agustín, y está claro que, al hacerla, Aquino mantenía el punto de vista aristotélico".
} 
En suma, no puede afirmarse que el bien humano se identifique enteramente con la consolidación de vínculos comunitarios fundados en las virtudes. Contrariamente, tampoco puede sostenerse que los buenos hábitos de carácter sean solo una "herramienta" para el logro de nuestra plenitud. Como sostiene el autor, las virtudes morales son "un componente fundamental de la vida buena del hombre", constituyen una parte integral de nuestra plenitud: vivir virtuosamente es ya, en gran medida, florecer ${ }^{20}$ : Una vez más, dice explícitamente Maclntyre (1999:112 [133]): “... los individuos y las comunidades solo pueden florecer de un modo específicamente humano mediante la adquisición y el ejercicio de las virtudes".

De manera análoga con lo sugerido respecto de los tipos de bienes, el autor propone también una nueva forma de "clasificar" las virtudes. Por un lado, distingue un grupo de virtudes para la actuación racional independiente. De otra parte, afirma la necesidad de reconocer un conjunto complementario de hábitos morales relacionados con el reconocimiento de la dependencia. El hombre es -para Maclntyre- no solamente un animal racional. El ser humano es, esencialmente, un animal racional y dependiente. En este sentido, solo podrá florecer si desarrolla virtudes en armonía con estas dos notas características de su naturaleza ${ }^{21}$. Las siguientes citas corroboran esta posición (1999: 8-9 [23]):

\footnotetext{
${ }^{20}$ A medida que se desarrolle este punto, se estará en condiciones de comprender mejor cuáles son los elementos constitutivos de la noción macintyreana -en gran medida metafórica- de florecimiento. Se trata para el autor de un término perfectamente intercambiable con la idea de buen vivir. Baste para mostrarlo la siguiente referencia (1999: 65 [83]): "En este sentido el concepto de florecimiento se asemeja a otros conceptos que implican usos del concepto básico de bien («florecer» se traduce como eu zen y bene vivere)". Dando un paso más en el uso de la metáfora, me atrevo a afirmar que la conquista del bien humano (su pleno conocimiento y posesión) podría ser entonces entendida como el "fruto maduro" de este florecer.

${ }^{21}$ Esta distinción es en el autor un corolario de sus más profundas convicciones respecto del pensamiento moral preponderante en nuestra cultura. Ya en Aristóteles pueden encontrarse los gérmenes de un cierto error a partir del cual se introdujo en la filosofía moral una estrecha vinculación entre las nociones de superioridad (moral) y autosuficiencia. Según MacIntyre, puede postularse a Aristóteles como "precursor" de nuestra incapacidad filosófica y cultural para reconocer la esencial vulnerabilidad y dependencia humanas. No obstante, es también verdad que en el propio Aristóteles se encuentran los mejores argumentos para enmendar esta equivocación: "Aristóteles puede ser corregido
} 
"La filosofía moral moderna ha puesto un gran énfasis en la autonomía del individuo, en su capacidad para formular elecciones independientes, lo cual es comprensible y correcto. Sin embargo, mi idea es que las virtudes de la actuación racional independiente sólo pueden ejercerse adecuadamente acompañadas de lo que denominaré las virtudes del reconocimiento de la dependencia y que si esto no se comprende, tampoco podrán verse con claridad ciertos rasgos de la actuación racional. Además, los dos conjuntos de virtudes son necesarios para realizar las potencialidades específicas que caracterizan al animal racional humano [...] la clase de vida que permite el florecimiento humano...".

Y también (1999: 120 [142]):

\begin{abstract}
"una buena educación en las virtudes será la que asigne un lugar adecuado a una serie de virtudes que son la equivalencia necesaria de las virtudes de la independencia: las virtudes del reconocimiento de la dependencia".
\end{abstract}

Las virtudes nos son necesarias no solo para consolidarnos en una forma de obrar racional independiente (es decir, un modo de actuar que no se muestre enteramente condicionado por los posibles juicios de aprobación o reprobación de nuestros semejantes). Necesitamos también otras virtudes para reconocer $y$, consiguientemente, asumir nuestra recíproca dependencia: hábitos morales que, por ejemplo, nos ayuden a tener la valentía de mostrarnos algunas veces "temerosos y frágiles" (es decir, verdaderamente humanos) frente a las personas que amamos; o disposiciones que nos permitan contener a quienes son excluidos por no contar con los recursos (fundamentalmente materiales y estéticos) que nuestra sociedad suele valorar en aquellos que triunfan.

Si bien este modo de "clasificar" las virtudes no se encuentra explícitamente mencionado en la tradición, sin embargo, el autor afirma que le fue inspirado por la lectura de Tomás de Aquino ${ }^{22}$. Al mismo tiempo, manifiesta que su propuesta lo pone

con Aristóteles. Aun cuando para ello se requiera, en ocasiones, la ayuda de Tomás" (Cfr. Maclntyre 1999: 7-8 [22]).

${ }^{22}$ Me parece interesante destacar aquí aquello que, en relación a las virtudes, constituye una propuesta "enteramente" macintyreana. Se trata de lo que el autor denomina como la virtud de un sentido 
un poco "a distancia" de algunos aspectos de la caracterización "puramente" aristotélica del hombre virtuoso. A continuación, se refiere a las diferencias que observa en el pensamiento de ambos autores (1999: xi [11]):

\begin{abstract}
"Pero me equivoqué al subestimar el grado y la profundidad de las diferencias en sus actitudes con respecto al reconocimiento de la dependencia [...] Esta idea se me ocurrió por primera vez al leer una oración de santo Tomás en que pide a Dios le conceda la posibilidad de compartir lo que tiene, felizmente, con aquellos que lo necesitan, y la posibilidad de pedir humildemente aquello que necesita a quienes lo poseen; aunque no estuviese en la intención de Santo Tomás, esta oración ruega, en efecto, no compartir algunas de las actitudes de megalopsychos de Aristóteles".
\end{abstract}

El autor no brinda, posteriormente, una enumeración detallada de las virtudes que específicamente pertenecen a cada uno de los grupos. Aun así, no sería difícil distinguir -de entre las virtudes propias de la tradición- cuáles de ellas contribuyen más particularmente al pleno ejercicio de la racionalidad práctica (fundamentalmente la prudencia) y cuáles nos disponen mejor para "movilizarnos" frente a las propias carencias (para -como afirma Tomás- "pedir humildemente aquello que necesitamos"), o bien para socorrer las necesidades de aquellos que están a nuestro lado ("para compartir generosa y desinteresadamente aquello en lo que abundamos" $)^{23}$. Aun así, lo importante para el presente estudio consiste en advertir la vinculación esencial que el autor establece entre las virtudes y el pleno ejercicio de la actuación racional en orden al fin último de la vida humana.

Este rodeo en torno al tema de las virtudes permite enfocar "bajo una nueva luz" las reflexiones precedentes referidas a nuestro conocimiento del bien humano. Las virtudes no solo nos permiten reconocer y valorar los diversos tipos de bienes; no solo nos posibilitan alcanzar la excelencia en las prácticas; ellas también nos "auxilian" en el

adecuado de las tradiciones a las que cada uno pertenece. Esta virtud pone asimismo de manifiesto cuáles son aquellas tradiciones con las que cada persona "naturalmente" se enfrenta (Cfr. Maclntyre 2007: 223 [275]).

${ }^{23}$ La virtud cristiana de la misericordia y aquella otra que el autor denomina justa-generosidad constituyen dos ejemplos de virtudes esenciales para el adecuado ejercicio de la actuación racional en el contexto del reconocimiento de una nuestra esencial dependencia comunitaria. 
conocimiento y persecución del telos (nos ayudan a no "distraernos" en la necesaria búsqueda de la vida buena). Vivir virtuosamente como padres, obreros y miembros de una asociación vecinal es -según se dijo-solamente una parte integral del vivir bien qua seres humanos. La buena vida como un todo no se "agota" en lo que podría llamarse dimensión subjetiva del florecimiento (el ejercicio fecundo de las virtudes en el contexto de las prácticas $\left.{ }^{24}\right)$. Por este motivo, urge dar "un paso más" en la argumentación a fin de proponer una respuesta más definida a la siguiente pregunta: ¿es posible encontrar en la obra de Maclntyre la afirmación expresa de un bien supremo objetivo (una dimensión objetiva del florecimiento) que sirva de horizonte último al conjunto de las acciones virtuosas?

Debe destacarse, una vez más, cuán esencial es a la actuación racional la "visión" de dicho telos. Ella proporciona una suerte de criterio para discernir la oportunidad de las diferentes acciones virtuosas: ¿cuál de estas acciones moralmente buenas (el ejercicio de qué práctica o papel social) me encamina mejor hacia el bien último de los seres humanos?, ¿cuál de ellas me permite, de alguna manera, "apropiarme" anticipadamente de él? MacIntyre confirma explícitamente esta posición (1999: 159 [187]): “...una justificación radical de la acción siempre será del tipo: «Porque actuar de esta determinada manera contribuirá a que yo alcance lo que es bueno para mí qua ser humano".

Sin embargo, el autor no se muestra tan "abierto" al momento de expresar su posición respecto de aquello que he denominado dimensión objetiva del florecimiento. Aun así, sus escritos proporcionan numerosas "pistas" sumamente valiosas al momento de intentar una respuesta. Por ejemplo, en Tras la Virtud describe -en forma

\footnotetext{
${ }^{24}$ Esta posición estaría, según el autor, enteramente de acuerdo con la concepción estoica de la virtud, la cual, es rechazada por MacIntyre debido al hecho de que en ella se abandona la idea de teleología, noción en la que encuentra su último sentido la práctica de las virtudes. La siguiente cita de Tras la Virtud muestra claramente lo aquí expresado (2007:233 [287]): “...cuando se abandona la teleología, aristotélica o cristiana, siempre existe la tendencia a sustituirla por una versión del estoicismo. Las virtudes no se han de practicar para obtener otro bien, o mejor dicho, un bien distinto de la práctica misma de las virtudes. La virtud es [...] su propio fin, su propia recompensa y su propio motivo".
} 


\begin{abstract}
“La divinidad impersonal e inmutable de la que habla Aristóteles, cuya contemplación metafísica procura al hombre su específico y último telos [...] Puesto que tal contemplación es el último telos humano, el ingrediente esencial y final que completa la vida del hombre que es eudaimon, existe cierta tensión entre la visión de Aristóteles del hombre como esencialmente político y su visión del hombre como esencialmente metafísico. Para llegar a ser eudaimon son necesarios requisitos materiales y sociales. La estirpe y la ciudad-estado hacen posible el proyecto humano metafísico; pero los bienes que proporcionan, aunque necesarios, aunque ellos mismos parte de la vida humana plena, están subordinados al punto de vista metafísico [...] Así, la autosuficiencia finalmente alcanzada por el hombre bueno en su contemplación de la razón eterna no conlleva que el hombre bueno no necesite amigos, como tampoco que no necesite un cierto nivel de prosperidad material. Paralelamente, una ciudad fundada en la justicia y en la amistad sólo puede ser el mejor tipo de ciudad si capacita a sus ciudadanos para disfrutar de la vida de la contemplación metafísica".
\end{abstract}

MacIntyre señala, en el pensamiento de Aristóteles, la posibilidad de una cierta "tensión" entre la afirmación del hombre como animal político y su definición como animal metafísico. Con todo, si bien ambas dimensiones se requieren y complementan el autor sostiene que la vida virtuosa consagrada al ámbito de las relaciones políticas ha de orientarse -como a su fin propio- hacia la contemplación de lo divino (una situación análoga se manifestó cuando se afirmó que los bienes externos debían ponerse al servicio de la excelencia). El ejercicio de las virtudes morales -algo que, no obstante, debe buscarse por sí mismo- no acaba con las posibilidades de

\footnotetext{
${ }^{25}$ MacIntyre es sumamente consciente de que es posible encontrar, dentro de la misma tradición clásica (fundamentalmente aristotélica), tanto en el pasado remoto como en el presente, formas diversas -ya divergentes; ya complementarias- a su particular modo de interpretar el pensamiento moral del estagirita. Nuestro autor considera este hecho como una "riqueza" que pone en evidencia la perenne fecundidad de dicha tradición. La siguiente cita confirma sobremanera esta posición (2007: 260 [319]): "El segundo conjunto de objeciones tendrá que ver con mi interpretación de lo que he llamado la tradición aristotélica o clásica. Porque está claro que la visión que he dado difiere por muchas maneras, algunas de ellas muy radicales, de otras aproximaciones e interpretaciones de la doctrina moral aristotélica. [...] Sin embargo, si mi visión de la naturaleza de la tradición moral es correcta, toda tradición se mantiene y progresa gracias a sus disputas y conflictos internos. Y aunque partes extensas de mi interpretación no resistieran la crítica, la demostración de ello fortalecería la tradición que intento mantener y extender".
} 
nuestra existencia. El conjunto de bienes materiales, corporales y espirituales que los buenos hábitos puedan "reportarnos", han de disponernos -personal y comunitariamente- al desarrollo y consolidación de nuestra dimensión contemplativa; han de proveernos de todo lo necesario para que podamos, regularmente, dedicarle cierto espacio de tiempo al conocimiento de "lo divino"; de aquello que, "desde arriba", puede iluminar y dotar de sentido al resto de nuestros humanos proyectos y aspiraciones. La buena vida humana no culmina en lo meramente humano. Parafraseando al propio Aristóteles, "no hemos de hacer caso a aquellos que nos dicen que, siendo mortales, hemos de vivir ocupándonos solo de las cosas humanas" (Cfr. EN 1177 b32).

Aun cuando la visión metafísica del telos humano formulada por Aristóteles no fue conocida en el occidente latino hasta aproximadamente el siglo XIII, los medievales compartieron en general la idea de que solo en Dios se encontraba el supremo bien de los seres humanos. Esta convicción se encuentra paradigmáticamente representada en la conocida sentencia agustiniana: "Nos hiciste Señor para Ti y nuestro corazón estará inquieto hasta que descanse en Ti" (Cfr. Confesiones I, 1.9). El autor confirma esta posición (2007: 175 [219]):

\footnotetext{
“Aristóteles tiene por telos de la vida humana cierta clase de vida [...] la vida buena tiene un telos que culmina en la contemplación de lo divino y por tanto, lo mismo para Aristóteles que para los medievales, la vida buena camina hacia un clímax".
}

Ahora bien, antes de "escuchar" a Maclntyre refiriéndose de un modo más directo a sus propias convicciones, conviene profundizar en aquello que sostiene respecto de la visión cristiano-tomista del telos humano. También aquí se mencionará primeramente aquello que el autor sostiene en Tras la Virtud (2007: [230]):

\footnotetext{
"La interpretación de las virtudes según el Nuevo Testamento, aunque difiere en contenido de la de Aristóteles [...] tiene su misma estructura lógica y conceptual. Una virtud es, como para Aristóteles, una cualidad cuyo ejercicio conduce al logro del telos humano. El bien del hombre es, por
} 
supuesto, sobrenatural y no sólo natural, pero lo sobrenatural redime y completa a lo natural. Además, la relación de las virtudes en tanto que medios para un fin [...] es interna y no externa, igual que en Aristóteles. Por descontado, este paralelismo es lo que permite a Tomás de Aquino realizar la síntesis entre Aristóteles y el Nuevo Testamento".

Como puede observarse, Maclntyre describe ahora un orden fundamentalmente religioso; el telos de la visión de la esencia de Dios -y consecuente unión de amor con Él- solo puede ser alcanzado, con el auxilio de la gracia, en la vida futura. Se trata de un fin sobrenatural cuyo logro excede las solas fuerzas humanas. En este sentido, necesita de la fe, esperanza y caridad (virtudes infusas), aun cuando también exija el esfuerzo permanente por consolidar las virtudes naturales. Pero, aun cuando "lo completa y redime", lo sobrenatural supone -se "apoya en"- lo natural. Y esto es, precisamente, lo que permitió al Aquinate realizar la síntesis entre ambos órdenes y, al mismo tiempo, reconocer la posibilidad de una felicidad imperfecta, aunque genuina, susceptible de ser alcanzada en este mundo. Tomás pensaba que en esta vida era posible y necesario al hombre conquistar una cierta dicha consistente en el ejercicio comunitario de las virtudes, entendido tanto como un bien en sí mismo como también al modo de propedéutica para el telos de un cierto conocimiento natural de Dios vislumbrado qua causa primera del ser y demás perfecciones del conjunto de las cosas (Cfr. MacIntyre 2009: 75 [127]). El hombre es un ser "capaz de Dios", posee las facultades necesarias para -ya desde ahora- comenzar a conocerlo y libremente amarlo. Sin embargo, esto depende en gran medida del hombre mismo, de su insobornable adhesión a la búsqueda de la excelencia moral, de su constancia en la fatigosa persecución de aquel saber metafísico que culmina en teología (una ciencia sumamente abstracta pero cuyas abstracciones tienen la mayor importancia vital). $Y$ esto mismo rememora el autor al referirse -ya más específicamente- a la posición del Aquinate (2009: 82 [137]):

“... [El hombre es] un ser capaz de conocimiento de Dios [...] alguien que se mueve por su propia naturaleza hacia unos fines últimos teóricos y prácticos, los fines de conocer y amar a Dios. La visión de Dios realiza y 
completa nuestras investigaciones en tanto que seres racionales. Según lo filósofos, la perfección última que puede alcanzar un alma es "tener inscriptos en sí misma todo el orden y las causas del universo [...] un fin que desde nuestro punto vista será la visión de Dios, porque, como Gregorio dice: "¿qué hay que no vean los que ven a quien ve todas las cosas?»" [...] las virtudes son precisamente esas cualidades que necesitamos para alcanzar nuestro bien. Sin embargo, que ésos son los fines a los que nuestra naturaleza humana se dirige es algo que nosotros, como agentes racionales, tenemos que aprender. Tenemos ciertamente las potencias necesarias para aprender cómo entender y cómo actuar con vistas a alcanzar esos fines a los que somos dirigidos por nuestra naturaleza, pero depende de nosotros desarrollar o no esas potencias del modo correcto" ${ }^{26}$.

El "pasar lista" a las descripciones que el autor realiza sobre las posiciones aristotélica y tomista acerca del supremo bien de los seres humanos permite "entrar en sintonía" con sus más personales convicciones respecto de este tema. Maclntyre gusta de expresar su propio pensamiento moral en el contexto de sus análisis histórico-críticos, con lo cual, en ocasiones resulta difícil "deslindar" su voz particular de las voces de aquellos a quienes estudia. No obstante, es manifiesto que cuando se habla de la tradición clásica -y especialmente de Aristóteles y del Aquinate- puede confiarse en que lo sostenido "armoniza" cabalmente con las posiciones macintyreanas. La siguiente cita muestra claramente cómo el autor asume para sí los desarrollos precedentes en referidos al telos humano (1992: 152 [163]):

\begin{abstract}
"Estas mismas afirmaciones requieren explicaciones sobre lo que para alguien significa triunfar o fracasar en el progreso hacia su último fin; pero tales explicaciones son de interés sólo y en cuanto que tenemos buenas razones para creer que son verdaderas. A su vez, tales explicaciones serán verdaderas si, y sólo si, el universo mismo está teleológicamente ordenado. Y el único tipo de universo teleológicamente ordenado en el que tenemos buenas razones para creer es un universo teísta. Entender esto es entender que el progreso moral de la persona corriente hacia su bien último es,
\end{abstract}

\footnotetext{
${ }^{26}$ Este aprendizaje supone en Tomás (del mismo modo que lo hacía para Aristóteles) la capacidad de reconocer $-\mathrm{y}$, consecuentemente, rechazar por no adecuarse a la razón- otras formas de orientar la existencia inconciliables con el pleno desarrollo de nuestra naturaleza. El autor lo indica en estos términos (2009: 89-90 [149]): "Tomás de Aquino cataloga doce concepciones diferentes de lo que es el bien humano, cada una de las cuales impondría un modo diferente de vida. De ellas, Tomás considera que once son erróneas. Entre esos modos de vida mal orientados estarían los que entienden que el bien primordial es la adquisición de dinero o la acumulación de poder o el logro de fama o gloria o la búsqueda del placer sensual o la perfección del cuerpo humano".
} 
aunque no siempre se reconozca, algo más que una cuestión de moralidad; es entender también que el relato contado de ese progreso moral sólo será plenamente inteligible cuando se comprenda bajo una adecuada luz teológica, es decir, cuando las particularidades de esa narración concreten lo que se dice en las cuestiones la-llae sobre el pecado y la gracia, la ley y las virtudes. El progreso moral de la persona comente siempre es el inicio de un progreso de peregrino".

El universo macintyreano constituye un cosmos teleológicamente ordenado que encuentra en Dios su último destino ${ }^{27}$. El hombre mismo, en tanto que parte de este mundo, es homo viator, ser que "va de viaje"; su vida es también un peregrinar hacia Dios ${ }^{28}$. El viaje mismo puede ser metafóricamente descripto como una "aventura moral", personal y comunitaria, atravesado por numerosos y bellos parajes que permiten "gustar" anticipadamente de la meta, pero también colmado de peligros y distracciones. Los vicios morales retrasan nuestra marcha y muchas veces nos apartan del camino. Las virtudes constituyen nuestro escudo y nuestra mejor defensa. El ejercicio de la racionalidad práctica es la luz para no perder de vista el sendero y en la amistad encontramos la fuerza necesaria para hacer frente a nuestra vulnerabilidad. Somos animales racionales y dependientes; fuimos "arrojados" a la existencia para alcanzar un horizonte último: el "telos de una vida humana completa" se encuentra en la búsqueda personal, familiar y comunitaria del conocimiento y amor de Dios. "El progreso moral de las persona corriente hacia su bien último es algo más que moralidad"; algo más que práctica de virtudes morales y cumplimiento de normas en el contexto de las prácticas.

Con esto se han podido dilucidar dos temas fundamentales. Por un lado, afirmo que es teóricamente justificado postular en el autor la existencia de una

\footnotetext{
${ }^{27} \mathrm{Mi}$ posición en este punto fundamental del pensamiento macintyreano coincide la lectura realizada por el ya mencionado Lorenzo Izquierdo (2007: 124): “Maclntyre [...] sí sostiene la tesis -aunque no la desarrolla- de que el teleologismo de la naturaleza humana es parte de la teleología del universo, que se dirige a Dios como a su fin.

${ }^{28}$ No es casual que esta forma de concebir la existencia coincida con aquello que en Tras la Virtud fue descripto como la estructura narrativa característica del modo cristiano-medieval de entender la vida humana. En palabras del autor (2007: 174-175 [218]): "En el esquema altomedieval, el género central es el relato de una búsqueda o viaje. El hombre está esencialmente in via. El fin que busca es algo que, si lo alcanza, puede redimir todo lo que hasta ese momento era malo en su vida".
} 
dimensión objetiva del florecimiento (2009: 5-6 [20]): "Y los seres finitos que poseen la facultad del entendimiento, si saben que Dios existe, saben que él es el objeto más adecuado de su amor".

De otra parte, sostengo que una consecuencia importante de dicha afirmación consiste en la posibilidad de vislumbrar aquello que sería una suerte de "criterio supremo" para el ejercicio práctico de la racionalidad, la "piedra de toque" para discernir la conveniencia particular de una acción virtuosa concreta (pues se ha visto ya que, para aquellos que buscan la excelencia moral, nunca es lícito preguntarse por la oportunidad de una acción deshonesta): elijo esta y no otra acción buena porque, dadas las particulares circunstancias en las que ahora me encuentro, ella es la que mejor puede predisponerme (no solamente a mí sino también a todos aquellos que viven conmigo y de los que, de algún modo, soy ineludiblemente responsable) a la conquista de los bienes superiores, en especial al conocimiento y amor de lo divino.

El vivir bien qua seres humanos. La vida buena "como un todo" y su esencial vinculación con la actuación racional. He aquí el núcleo de las reflexiones a las que se consagró el presente punto. La buena vida humana exige de todos, personas y comunidades, un compromiso continuado con la búsqueda de lo que significa vivir bien (esto, según se dijo, es ya adentrarse en la senda de la buena vida. Contrariamente, desentenderse de la búsqueda, es ya un síntoma de fracaso). Resultado de dicha indagación compartida será la obtención de una comprensión cada vez más adecuada de los diversos tipos de bienes y del supremo bien de los seres humanos. Se aprenderá también el valor de las prácticas como espacio en el que -mientras se buscan los bienes internos pertenecientes a una actividad-se aprenden y se ejercen las virtudes. Perseguir la excelencia qua padres, filósofos, directores de enseñanza o encargados del mantenimiento de una fábrica es ya -según se dijo- una parte integral del buen vivir humano. Pero todo ello encuentra su sentido último en la medida en que pueda orientarse al conocimiento y adhesión de aquel Bien que está más allá de lo político: avanzamos o dejamos de avanzar hacia el conocimiento y amor de lo divino. Este Bien 
ha de constituirse en principio primero de la deliberación racional (lo último en ser plenamente alcanzado pero lo primero en la intención de los agentes), en supremo “criterio" para la toma de decisiones prácticas ${ }^{29}$ : priorizamos esta actividad en desmedro de esta otra, ejercemos esta virtud en lugar de aquella, porque reconocemos que dicha elección nos dará "más espacio" para trascender -junto a otros (familiares, amigos, compañeros de comunidad)- el ámbito de lo meramente útil, el ámbito de lo consagrado a la sola supervivencia o mera "comodidad" de la existencia. "Lo moral no se resuelve en lo moral"; "lo humano no se agota en lo meramente humano".

Buscar junto a otros el único Bien que vale enteramente por sí mismo; buscar el fundamento último de nuestra existencia; buscarlo mediante deliberaciones compartidas, a través de peleas familiares o discusiones académicas; buscarlo mientras nos entregamos al ejercicio de las virtudes y a la excelencia en el cumplimiento de nuestros papeles sociales. Todo ello sería para Maclntyre, vivir bien qua seres humanos.

\footnotetext{
${ }^{29}$ Se vuelve ahora enteramente patente el irreconciliable contraste entre la posición macintyreana y la singular caracterización que la cultura contemporánea hace de los bienes. De este particular "espíritu de época" el autor objeta no solamente la afirmación de que es imposible proponer una ordenación jerárquica y objetiva de los bienes, sino también la consideración de que la tradicional aspiración a unificar, en torno a un determinado bien supremo, las diversas metas posibles de una persona constituye algo absurdo e irracional. Este tema aparece, de un modo u otro, en las principales obras de nuestro autor. A modo de ejemplo, baste la siguiente referencia (1988: 337 [321]): "Y la educación en la cultura de un orden liberal es, por tanto, característicamente, el llegar a ser ese tipo de persona a quien le parece normal que una variedad de bienes se persiga, cada uno apropiado a su propia esfera, sin ningún bien global que proporcione unidad total a la vida".
} 


\section{Referencias}

MacINTYRE, Alasdair. (1981) After Virtue: A Study in Moral Theory Duckworth \& Co., London; y: University of Notte Dame Press, Notre Dame (Indiana). En este trabajo las referencias de página se indican según la $3^{\circ}$ edición (2007) University of Notre Dame Press, Notre Dame (Indiana). Trad. española: (1987) Tras la Virtud, trad. Amelia Varcárcel, Ed. Crítica, Barcelona. Las referencias a la paginación del texto en español se toman de la Segunda edición en Biblioteca de Bolsillo (2004).

MacINTYRE, Alasdair. (1988) Whose Justice? Which Rationality? University of Notre Dame Press, Notre Dame (Indiana). Trad, española: (1994) Justicia y Racionalidad, trad. Alejo G. Sison, Ed. Eunsa, Madrid. Las referencias a la paginación del texto en español se toman de la Segunda edición (2001).

MacINTYRE, Alasdair. (1990) Three Rival Versions of Moral Enquiry: Encyclopedia, Genealogy, and Tradition, The Gifford lectures delivered in 1988 in Univ. of Edimburg, Notre Dame University Press, Notre Dame (Indiana). Trad. española (1992): Tres Versiones Rivales de la Ética, trad. Rogelio Rovira, Ed. Rialp, Madrid.

MacINTYRE, Alasdair. (1992) Plain Persons and Moral Philosophy: Rules Virtues and Goods (Conferencia Tomás de Aquino de 1991 en Univ. Dallas), American Catholic Philosophical Quarterly, v. 66, n1 (Winter), pp. 3-20. Reimpreso en: (1998). The MacIntyre Reader, Kelvin Knight, University of Notte Dame Press, Notre Dame (Indiana). Las citas se toman de la edición en este libro. Traducción reimpresa en Mauri, M.; Román, B et al. (1997) Crisis de Valores, Modernidad y tradición (Un profundo estudio de la obra de A. Maclntyre), EditEuro, Barcelona. La página de la traducción se toma de este libro.

MacINTYRE, Alasdair. (1999) Dependent Rational Animals: Why Human Beings Need the Virtues, Open Court Publishing, Chicago and La Salle (Illinois). Trad. española (2001) Animales Racionales y Dependientes: Por qué los seres humanos necesitamos virtudes, Trad. Beatriz Martínez, Ed. Paidos, Barcelona. 
MacINTYRE, Alasdair. (2006) Ethics and Politics. Selected Essays II, Cambridge University Press, New York. Trad. Española (2008) Ética y Política. Ensayos escogidos II, Trad. Sebastian Montiel, Ed. Nuevo Inicio, Granada.

MacINTYRE, Alasdair. (2009) God, Philosophy, Universities: A Selective History of the Catholic Philosophical Tradition, Rowman \& Littlefield Publishers, Lanham (Maryland). Trad Española (2012) Trad. Enrique Anrubia y Sebastian Montiel, Ed. Nuevo Inicio, Granada.

ARISTÓTELES, (1982) Ética Nicomáquea, Ed. Gredos, Madrid.

AGUSTín DE HIPONA, (1955) Confesiones, Obras T. II, Ed. B.A.C, Madrid.

DE LA TORRE, Javier, (2005) Alasdair MacIntyre ¿un crítico del liberalismo? Creencias y virtudes entre las fracturas de la modernidad, Ed. Dykinson, Madrid.

GARCÍA LÓPEZ, Jesús (1985) Tomás de Aquino, Maestro del Orden, Ed. Cincel Kapelusz, Bogotá.

GARCÍA LÓPEZ, Jesús. (2001) Metafísica Tomista: Ontología, Gnoseología y Teología natural, Ed. Eunsa, Navarra.

IZQUIERDO, David Lorenzo, (2007) Comunitarismo contra individualismo: Una revisión de los valores de Occidente desde el pensamiento de Alasdair Maclntyre, Ed. Aranzadi, Navarra.

PLATÓN, (1982) Apología de Sócrates, en Diálogos I, Ed. Gredos, Madrid TOMÁS DE AQUINO, (2006) Suma de Teología, Ed. B.A.C, Madrid. 